11

\title{
Источники радиоосвещения на основе сверхширокополосных микрогенераторов хаотических колебаний
}

\author{
() А.С. Дмитриев, Е.В. Ефрремова
}

Институт радиотехники и электроники им. В.А. Котельникова РАН, Москва E-mail: chaos@cplire.ru

Поступило в Редакцию 17 июля 2016 г.

Рассматривается задача освещения предметов и поверхностей искусственными некогерентными источниками микроволнового излучения с целью их последующего наблюдения с помощью радиометрической аппаратуры. Одной из основных проблем при реализации этой задачи является создание эффективных источников самого микроволнового излучения, подобных осветительным устройствам в видимом диапазоне света. Предлагается в качестве источников некогерентного широкополосного микроволнового излучения использовать генераторы сверхширокополосных хаотических колебаний. Описываются экспериментальный образец такого источника, реализованный в виде микрогенератора хаоса на основе кремниево-германиевого кристалла, и его характеристики.

Под радиоосвещением будем понимать искусственно созданное шумовое (шумоподобное) поле широкополосного (сверхширокополосного) некогерентного в пространстве и во времени излучения в радио- или микроволновом диапазоне длин волн. Радиоосвещение реализуется с помощью одного или нескольких источников широкополосного (сверхширокополосного) некогерентного микроволнового излучения. Попадая на близлежащие поверхности и предметы, микроволновое излучение частично поглощается в них, частично проходит через них и частично отражается. Тем самым, распространяясь далее, оно несет в себе информацию о среде, с которой взаимодействует. В этом отношении ситуация аналогична ситуации с обычным (видимым) светом. Разница в том, что это другой частотный диапазон и другие законы взаимодействия со средой, в которой происходит процесс. Кроме того, для обычного света имеется такой замечательный инструмент наблюдения, как глаз. Для извлечения информации об объектах, находящихся в зоне радиоосвещения (радиосвета) нужны специальные датчики или системы таких 
датчиков. Аналогия между радиоосвещением и обычным освещением в видимом глазом диапазоне электромагнитного спектра достаточно глубокая [1]. В обоих случаях речь идет о некогерентном излучении с широким спектром, что исключает эффекты интерференции и сводит вопросы наблюдения к оценке мощностных (и, возможно, спектральных, как в случае цветного зрения) характеристик принимаемого сигнала. Принципиальной особенностью радиоосвещения по отношению к обычному свету является разница в характерном диапазоне частот (примерно на пять порядков) для света и радиосвета. Последнее означает существенно более низкую потенциальную разрешающую способность при использовании радиоосвещения по сравнению с видимым светом. Однако, очевидно, существует достаточно много ситуаций, когда это либо приемлемо, либо не имеет принципиального значения.

Наблюдения объектов с помощью некогерентного микроволнового излучения и других некогерентных сигналов в отличных от частот видимого света диапазонах частот давно и плодотворно используется, например, в космических исследованиях, при наблюдении Земли из космоса $[2-4]$ и в медицинской диагностике $[5,6]$. При этом используется некогерентное микроволновое излучение, порождаемое естественными процессами, такими как собственное тепловое излучение физических тел в микроволновом диапазоне, или рассеяние микроволнового излучения, создаваемого мощными естественными источниками (например, Солнцем). Еще одним активно развивающимся направлением использования некогерентного микроволнового излучения для наблюдения объектов являются радиометрические системы с использованием шумовой подсветки [7,8]. В таких системах на радиометре размещается направленный источник искусственного некогерентного электромагнитного излучения, который подобно прожектору в оптическом диапазоне подсвечивает наблюдаемую область пространства. Наиболее перспективными для систем с подсветкой считаются миллиметровый и субмиллиметровый (терагерцовый) диапазоны частот. Таким образом, имеется большой массив информации, который может дать ответы как минимум на ряд исходных вопросов, связанных с радиоосвещением и присущими ему свойствами. Однако сама, достаточно очевидная, идея радиоосвещения с помощью локальных искусственных источников, подобных осветительным приборам в видимом диапазоне электромагнитного спектра, упоминается в литературе как некая экзотика (см., например, [1]). 
Одной из причин такого положения является отсутствие эффективных источников некогерентного микроволнового излучения, которые могли бы быть использованы для радиоосвещения. Действительно, это должны быть устройства, которые излучают достаточно мощные по сравнению с тепловым излучением шумовые или шумоподобные широкополосные сигналы. В эксплуатации они должны быть простыми и похожими на источники обычного света типа ламп накаливания, люминесцентных ламп, светодиодных ламп и т.п. В противном случае речь о радиоосветительных приборах может идти только применительно к специальной исследовательской аппаратуре.

В микроволновой технике используются два типа источников шума: газоразрядные трубки и полупроводниковые $p$-n-диоды в режиме лавинного пробоя. Их основным параметром является коэффициент избыточности шума (excess noise ratio - ENR), который определяется как отношение сгенерированной мощности шума к мощности шума резистора, согласованного с конкретной линией передачи, при температуре окружающей среды и измеряется в $\mathrm{dB}$. Газоразрядные трубки имеют типичный ENR $15 \mathrm{~dB}$, что примерно в 30 раз больше мощности теплового шума, создаваемого согласованным резистором при температуре окружающей среды $290 \mathrm{~K}$. Таким образом, трубка генерирует шум, соответствующий температуре примерно $9 \cdot 10^{3} \mathrm{~K}$. Значение ENR для диодных источников шума достигает $30 \mathrm{~dB}$, и их шумовая температура имеет величину около $3 \cdot 10^{5} \mathrm{~K}$, что соответствует спектральной плотности мощности $p \approx 4 \cdot 10^{-9} \mathrm{~mW} / \mathrm{MHz}(-84 \mathrm{dBm} / \mathrm{MHz})$. Дальнейшее повышение ENR может быть достигнуто за счет применения усилителей. Однако при существенном повышения выходной мощности требуется достаточно сложная и недешевая конструкция. Таким образом, ни один из этих типов источников шума не может рассматриваться как подходящее решение для источников радиоосвещения.

В данной статье в качестве источников для радиоосвещения предлагается использовать генераторы динамического хаоса, которые можно рассматривать как источники шумоподобных аналоговых сигналов в соответствующем диапазоне частот.

Эти устройства прошли долгий путь эволюции от вакуумных приборов, использующих естественное запаздывание в распределенных системах, к полупроводниковым устройствам с распределенными колебательными системами на основе микрополосков и далее к полупроводниковым устройствам с колебательными системами на элементах с

4* Письма в ЖТФ, 2016, том 42, вып. 24 

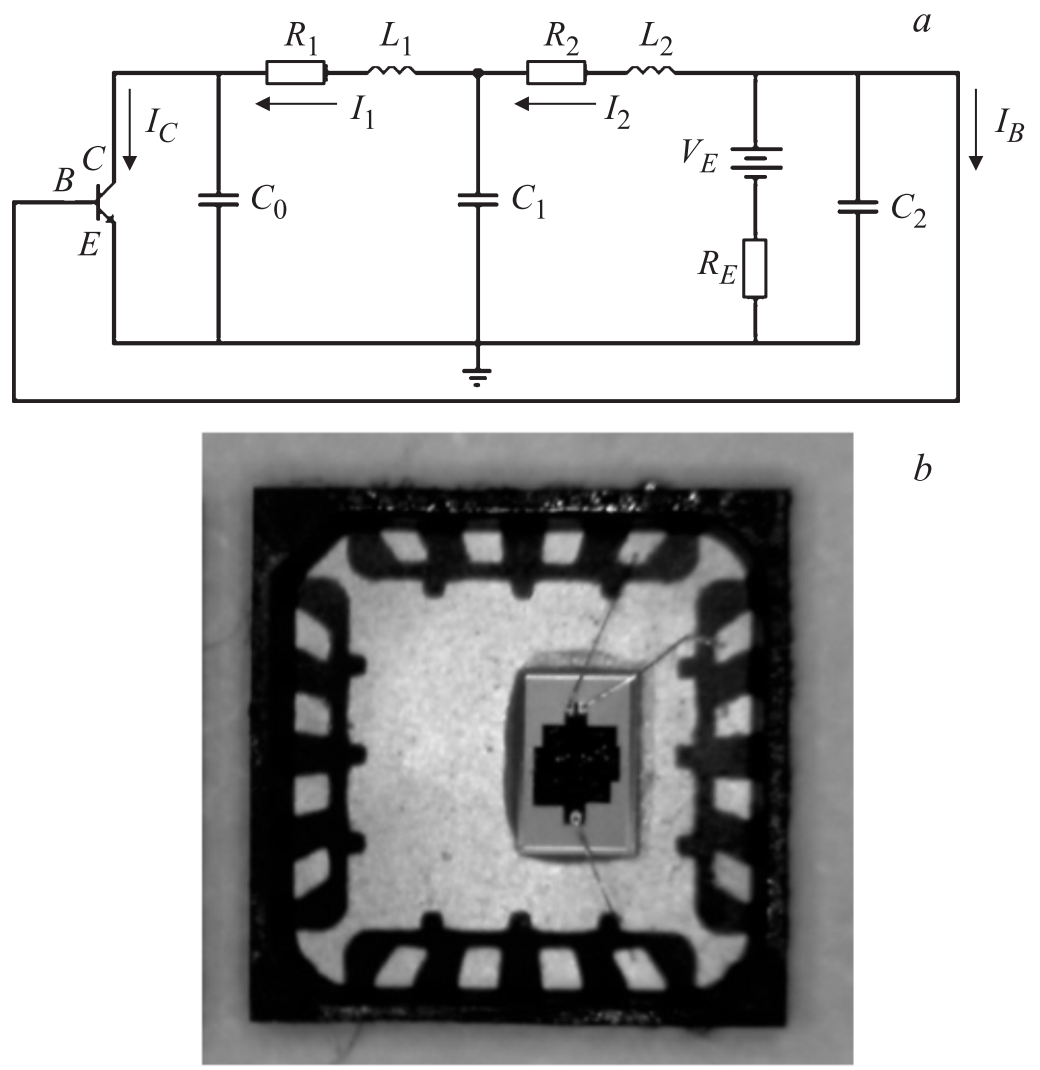

$b$

Рис. 1. Микрогенератор сверхширокополосных хаотических колебаний: $a$ - автоколебательная система генератора; $b-$ кремний-германиевый кристалл в корпусе; $c$ - спектр мощности генерируемого сигнала.

сосредоточенными параметрами [9]. При этом речь идет об устройствах, генерирующих хаотические сигналы в заданном диапазоне радио- или микроволновых частот. Типичный генератор хаоса микроволнового диапазона с сосредоточенными параметрами реализуется на основе автоколебательной системы с 2.5 степенями свободы, активным элементом которой является биполярный транзистор (рис. $1, a$ ).

Письма в ЖТФ, 2016, том 42, вып. 24 


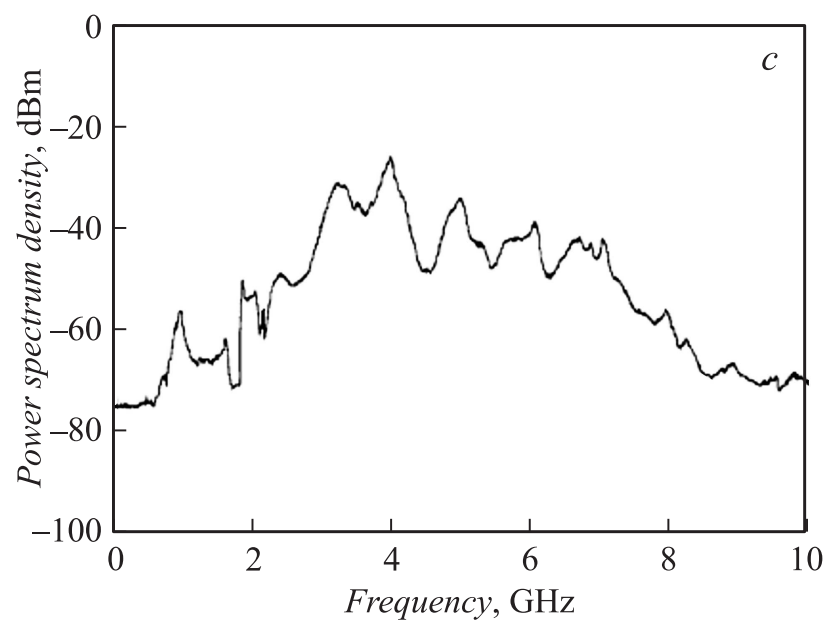

Рис. 1 (продолжение).

Математическая модель генератора представляет собой систему из 5 обыкновенных нелинейных дифференциальных уравнений первого порядка:

$$
\begin{aligned}
& C_{0} \dot{V}_{C E}=I_{1}-I_{C}, \\
& L_{1} \dot{I}_{1}=V_{1}-V_{C E}-R_{1} I_{1}, \\
& C_{1} \dot{V}_{1}=I_{2}-I_{1}, \\
& L_{2} \dot{I}_{2}=V_{B E}-V_{1}-R_{2} I_{2}, \\
& C_{2} \dot{V}_{B E}=\left(V_{E}-V_{B E}\right) / R_{E}-I_{2}-I_{B},
\end{aligned}
$$

где $V_{C E}, V_{B E}$ - напряжения коллектор-эмиттер и база-эмиттер; $V_{1}-$ напряжение на емкости $C_{1} ; I_{1}, I_{2}, I_{C}, I_{B}$ - токи через индуктивность $L_{1}$, индуктивность $L_{2}$, коллектор $C$ и базу $B$ транзистора. Структура этой автоколебательной системы такова, что генерируются колебания в некоторой полосе частот. При этом генерация в требуемой полосе частот и хаотический характер колебаний обеспечиваются соответствующим выбором параметров автоколебательной системы [9]. На основе генераторов микроволнового хаоса работают сверхширокополосные

Письма в ЖТФ, 2016, том 42, вып. 24 
приемопередатчики для беспроводной связи и беспроводных сенсорных систем [10].

Следующим шагом в миниатюризации и повышении технологичности генераторов хаоса является создание генераторов хаоса на основе автоколебательных систем типа (1) в виде интегральных микросхем. Работы в этом направлении начались несколько лет назад. В частности, в монолитной интегральной схеме на основе $\mathrm{SiGe}$ были получены хаотические колебания в диапазоне $3-8 \mathrm{GHz}$ с выходной мощностью $50 \mu \mathrm{W}$ [11]. К настоящему времени в ИРЭ им. В.А. Котельникова РАН получены экспериментальные образцы микрогенераторов хаоса в диапазоне частот $3-7 \mathrm{GHz}$ с интегральной мощностью излучения около $300 \mu \mathrm{W}$ (рис. $1, b, c)$. В приборах используется кремний-германиевая технология $0.25 \mu \mathrm{m}$. Площадь кристалла $1.6 \mathrm{~mm}^{2}$.

Создание генераторов динамического хаоса в виде микросхем принципиально меняет ситуацию в области производства: теперь источники некогерентных сверхширокополосных шумоподобных сигналов микроволнового диапазона можно изготавливать массово и с низкой себестоимостью. Поэтому появляется возможность расширить области их применения на новые задачи, и радиоосвещение - одна из таких задач.

Ближайшими аналогами источников микроволнового некогерентного сверхширокополосного излучения в видимом глазом диапазоне являются светодиоды с белым свечением. Подобно тому, как такие светодиоды являются эффективными источниками широкополосного некогерентного излучения в видимом диапазоне частот, микрогенераторы динамического хаоса являются эффективными источниками широкополосного некогерентного излучения в микроволновом диапазоне частот.

Действительно, светодиоды (с белым свечением) излучают некогерентный шумовой сигнал в полосе длин волн $\Delta \lambda=650-450 \mathrm{~nm}$. При этом полоса частот белого света с радиофизической точки зрения является сверхширокой, поскольку $\Delta f / f=\Delta \lambda / \lambda>0.25$, где $\Delta f-$ разница между верхней и нижней частотами в спектре излучения, а $f$ и $\lambda$ - средняя частота и средняя длина волны в спектре соответственно.

Аналогия микрогенератора хаоса по спектральным характеристикам со светодиодами белого свечения становится очевидной, если посмотреть на огибающую спектра мощности сигнала микрогенератора (рис. $1, c)$. Анализ характеристик модели микрогенератора показал, что

Письма в ЖТФ, 2016, том 42, вып. 24 


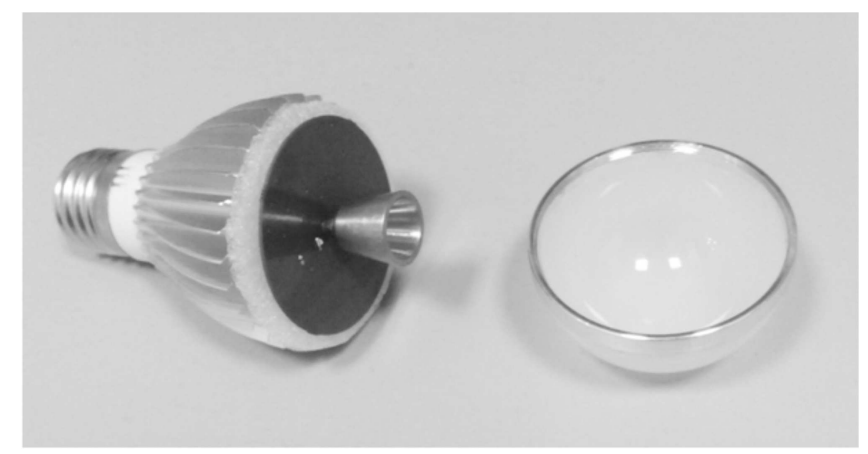

Рис. 2. Лампа для радиоосвещения с активным элементом на кремнийгерманиевом микрогенераторе хаотических колебаний.

реализация процесса имеет шумоподобный вид, автокорреляционная функция быстро спадает, статистическое распределение мгновенных значений сигнала близко к гауссовскому. Таким образом, хаотический сигнал обладает характеристиками, обеспечивающими создание некогерентного освещения в микроволновом диапазоне частот.

Важным общим свойством микрогенераторов динамического хаоса и светодиодов является некогерентность генерируемого сигнала. Это свойство принципиально для применения микрогенераторов хаоса в качестве источников освещения, поскольку обеспечивает равномерную, без интерференции засветку окружающей среды при использовании как одиночного, так и множественных источников. Еще одной общей чертой светодиодов и микросхем генераторов хаоса (chaos emitted chip - CEC) является сходство в электрических характеристиках: оба типа устройств являются низковольтными и могут применяться как поодиночке, так и в виде последовательных и параллельных сборок, в том числе в целях увеличения мощности или распределения излучения по пространству.

Например, по аналогии со светодиодной лампой может быть создана лампа для радиоосвещения с активным элементом в виде микросхемы. Экспериментальный образец радиоосветительной лампы представлен на рис. 2. Он разработан на основе описанной выше микросхемы генератора хаотических колебаний. Конструктивно лампа включает в себя плату с электронными компонентами, антенну и источник

Письма в ЖТФ, 2016, том 42, вып. 24 
вторичного питания, обеспечивающий преобразование сетевого переменного напряжения $220 \mathrm{~V}$ в напряжение постоянного тока $5 \mathrm{~V}$. Верхняя металлизированная сторона платы вместе с конусным элементом образует дискополиконическую излучающую антенну [12]. Кроме того, на верхней стороне платы расположен индикаторный светодиод, отображающий состояние устройства (включено или выключено). Электронная часть лампы размещена в стандартном покупном корпусе для светодиодных ламп с радиопрозрачной пластмассовой полусферой и цоколем типа Е27. Вторичный источник питания находится в цоколе лампы. Лампа излучает в широком диапазоне углов симметрично относительно продольной оси.

Создание радиоосвещения в помещении или на открытой площадке сводится к ввинчиванию лампы радиоосвещения в обычный патрон стандартного светильника и нажатию кнопки выключателя.

Детальное обсуждение аппаратуры для наблюдения радиоосвещенных объектов и самого процесса наблюдения выходит за рамки данной работы. Отметим только, что прототипами таких приборов могут быть традиционные радиометрические приемники [2-6] и датчики на основе логарифмических детекторов [10]. Последние обладают достаточно высокой чувствительностью и большим динамическим диапазоном. Так, например, приемник с логарифмическим детектором и ненаправленной антенной будет „чувствовать“ радиосвет лампы с мощностью излучения $300 \mu \mathrm{W}$ на расстояниях от десятков сантиметров до нескольких сотен метров.

Авторы благодарят М.Е. Герасимова, В.В. Ицкова, В.А. Калошина и К.3. Нгуена за помощь в подготовке экспериментов. Исследование выполнено за счет гранта Российского научного фонда (проект № 1619-00084).

\section{Список литературы}

[1] Polivka J., Fiala P., Machac J. // Prog. Electromagn. Res. 2011. V. 111. P. 311330.

[2] Шутко А.М. СВЧ-радиометрия водной поверхности и почвогрунтов. М.: Наука, 1986.

[3] Armand N.A., Polyakov V.M. Radio Propagation and Remote Sensing of the Environment. N.Y.: CRC Press, 2005.

Письма в ЖТФ, 2016, том 42, вып. 24 
[4] Кутуза Б.Г., Данильчев М.В., Яковлев О.И. Спутниковый мониторинг Земли: микроволновая радиометрия атмосферы и поверхности. M.: URSS, 2015.

[5] Гуляев Ю.В., Годик Э.Э. // Вестник АН СССР. 1983. № 8. С. 118-125.

[6] Гуляев Ю.В. Физические поля и излучения человека. Новые неинвазивные методы медицинской диагностики. М.: РБОФ „Знание“ им. С.И. Вавилова, 2009.

[7] Пелюшенко С.А., Ракуть И.В., Железняков Ю.А., Пелюшенко А.С. // Изв. вузов. Радиофизика. 2005. Т. 48. № 10-11. С. 890-898.

[8] Ивашов С.И., Бугаев А.С. // РЭ. 2013. Т. 58. № 9. С. 935-942.

[9] Дмитриев А.С., Ефремова Е.В., Максимов Н.А., Панас А.И. Генерация хаоса. М.: Техносфера, 2012.

[10] Дмитриев А.С., Клещов А В., Лактюшкин А.М. // РЭ. 2006. Т. 51. № 10. C. $1193-1209$.

[11] Дмитриев А.С., Ефремова Е.В., Никишов А.Ю. // Письма в ЖТФ. 2009. T. 35. В. 23. C. $40-46$.

[12] Калочин В.А., Мартынов Е.С., Скородумова Е.А. // РЭ. 2011. Т. 56. № 9. C. $1094-1098$. 